\title{
ROAD SAFETY ASSESSMENT CONSIDERING THE EXPECTED FATAL ACCIDENT DENSITY
}

\author{
VILMA JASIŪNIENE' ${ }^{1 *}$, RASA VAIŠKŪNAITE் ${ }^{2}$ \\ ${ }^{1}$ Road Research Institute, Vilnius Gediminas Technical University, \\ Vilnius, Lithuania \\ ${ }^{2}$ Dept of Environmental Protection and Water Engineering, \\ Vilnius Gediminas Technical University, Vilnius, Lithuania
}

Received 3 February 2020; accepted 24 February 2020

\begin{abstract}
Network-wide road safety assessment throughout the whole network is one of the four road infrastructure safety management procedures regulated by Directive 2019/1936/EC of the European Parliament and of the Council of 23 October 2019 Amending Directive 2008/96/EC on Road Infrastructure Safety Management and one of the methods for determining the direction of investment in road safety. So far, the implementation of the procedure has been lightly regulated and adapted using various road safety indicators. The paper describes the evaluation of road accident data that is one of the criteria for conducting a network-wide road safety assessment. Taking into consideration that networkwide road safety assessment is a proactive road safety activity, the paper proposes to conduct road safety assessment considering the expected fatal accident density. Such assessment makes it possible to assess the severity of accidents, and the use of the predicted road accident data on calculating the introduced road accident rate contributing to the prevention of accidents. The paper describes both the empirical Bayes method for predicting road accidents and the application of one of the road safety indicators - the expected fatal accident density - to determine five road safety categories across the road
\end{abstract}

\footnotetext{
* Corresponding author. E-mail: vilma.jasiuniene@vgtu.lt

Vilma JASIŪNIENE (ORCID ID 0000-0002-6093-2825)

Rasa VAIŠKŪNAITĖ (ORCID ID 0000-0003-0881-7608)

Copyright (C) 2020 The Author(s). Published by RTU Press

This is an Open Access article distributed under the terms of the Creative Commons Attribution License (http://creativecommons.org/licenses/by/4.0/), which permits unrestricted use, distribution, and reproduction in any medium, provided the original author and source are credited.
} 
network. The paper demonstrates the application of the proposals submitted to Lithuanian highways using road accident and traffic data for the period 2014-2018.

Keywords: expected road fatalities, fatal accident density, network-wide road safety assessment, road accident, road safety.

\section{Introduction}

Over a few recent decades, the road safety situation of the Member States of the European Union (EU) has significantly improved because of multidisciplinary efforts undertaken at European, national, regional, and local levels. Although the number of road fatalities in the EU has fallen by as much as $45.72 \%$ for the period 2001-2018, however, the observed progress has slowed down significantly over the last five years, i.e. the number of road fatalities has remained almost unchanged across the EU. The road accident trends show that both long and short-term EU road safety objectives in the field of traffic safety (European Commission, 2019) will be hardly completed because a new way of thinking and appropriate measures for road accidents prevention are needed. Reducing the number of road accidents is also essential bearing in mind another presently relevant environmental aspect. An increase in traffic safety reduces traffic congestion thus decreasing vehicle emissions (up to $10-20 \%$ ) and improving ambient air quality both for those involved in traffic and those living next to heavy traffic. In addition, different types of pollutants $\left(\mathrm{NO}_{\mathrm{X}}, \mathrm{PM}_{10}, \mathrm{CO}, \mathrm{SO}_{2}\right.$, benzene, lead) are emitted to the environment under the frequent occurrence of road accidents (Henneman, Chang, Liao, Lavoué, Mulholland, \& Russell, 2017; van Erp, O'Keefe, Warren, C., \& Warren, J., 2008).

Everyone is involved in traffic. Nevertheless, all road user roles are very different starting from the one they play (driver, pedestrian, cyclist, passenger), age and health state to the different levels of preparation, experience, lack of skill. Traditionally, a person is a key component of the road safety system (Farooq, Moslem, \& Duleba, 2019; Treat, Tumbas, McDonald, Shinar, Hume, Mayer, ... \& Castellan, 1979) and the right or wrong decisions and actions they make are at risk of a road accident. Behavioural changes are prolonged and progressive, and therefore hardly produce the expected results. Also, educating a road user to behave safely is inappropriate in a system built to be inherently unsafe (Varhelyi, 2016). The ambitious long-term goal of the EU to move close to zero fatalities by 2050 is based on the Safe System approach (European Commission, 2019). People rather than their behaviour are at the centre of the system. 
Regarding this approach, first, people make mistakes leading to road accidents; however, no one should die or be seriously injured on the road because of these mistakes. Second, the human body has a limited physical ability to tolerate crash forces. With that in mind, the road system needs to put the layers of protection in the form of safe roads, vehicles, speeds, and people around the fallible and vulnerable human to prevent fatal and serious injury road accidents (European Commission, 2019).

Progress in decreasing the number of injury road accidents varies widely across the EU Member States. Reduction in road fatalities by the EU country between 2010 and 2017 show the mortality rate ranging from $-41 \%$ to $+46 \%$ (EU average - 20\%) (European Commission, 2019). Because of the specified road accident situation, considering the principles of the Safe System approach and addressing the problem at the EU level, a Directive 2019/1936 was approved by the European Parliament in 2019 and which partially amended Directive 2008/96/ EC on Road Infrastructure Safety Management (Directive 2019/1936 of the European Parliament and of the Council of 23 October 2019 Amending Directive 2008/96/EC on Road Infrastructure Safety Management). The main objectives of the Directive 2019/1936 include improvements to procedures for road infrastructure safety management and the way they are carried out considering the prevailing trends in mobility thus paying attention to vulnerable users to extend the scope of the Directive $2019 / 1936$.

One of the significant changes in the Directive 2019/1936 is related to introducing a new procedure called a network-wide road safety assessment replacing the system for determining road network safety levels. The procedure is aimed at creating a system for assessing the entire road network acting as a systematic and proactive risk assessment procedure for evaluating inherent road safety risks throughout the EU. For assessing the road safety of the whole network, the EU Member States should consider the traffic volume, road accident data, operational and geometric road characteristics, crossings, maintenance, vulnerable facilities of road users. Subject to the findings of the carried-out assessment, the EU Member States will have to divide the examined road links into at least three categories in according to their level of safety. The Commission shall provide guidance on the methodology for carrying out systematic network-wide road safety assessment and safety ratings to achieve a uniform procedure (Directive 2019/1936). This article suggests the way of assessing one of the recommended criteria, i.e. road accident data performing network-wide road safety assessment.

For several decades, reducing road accidents in terms of road infrastructure has been addressed in "black spots"; i.e. certain links 
containing the concentrated fatal historic road accidents. Black spots are most frequently of restricted visibility and occur at single-level crossings, bus stop access, low visibility road links with small radius vertical and horizontal curves, road links having trees near the carriageway and other road links where certain features of the road or its surroundings increase risk of being involved in a road accident. A statistical definition of a black spot relies on a comparison of the recorded number of road accidents for a similar type of location (Sørensen \& Elvik, 2007). Literature analysis shows there is hardly uniform definition and calculation methodology for black spots (Elvik, 2004; Hauer, 1996; Sørensen \& Elvik, 2007). The basic elements defining blackspots include the number of road accidents, the length of road links and the period of analysis. Literature analysis also provides that all these criteria differ in various methods used for calculating black spots.

Nevertheless, these are usually short road links varying in length from $100 \mathrm{~m}$ to $500 \mathrm{~m}$ (Alonso, F., Alonso, M., Esteban, \& Useche, 2016; Sørensen, \& Elvik, 2007). To avoid "black spot" migration, minimize the impact of year-on-year variability in accident numbers and present a stable longer-term estimate of road accident risk (RAP-RM-2.1: RAP Road Risk Mapping Manual: Technical Specification), solving road safety problems on longer road links is recommended. Thus, in this context and view of a decreasing number of "black spots", the assessment of the entire road network is a useful and timely tool for improving road safety.

Different rates are used to determine and prioritise the risk of road sections at the road network level. Subject to the availability of the required data on identifying the risk level, road accident rate (González, Ponce, \& Sotos, 2020), road accident density (Strawderman, Rahman, Huang, \& Nandi, 2015) and road accident cost rates are employed. Typically, the above indicators are calculated using historical road accident data, i.e. define the current network safety level. Based on the proactive approach that prevention is better than cure, the authors of this paper aim at replacing historical road accident data with the expected road accident data and their relative indicators. In this case, the application of the expected road accident data focuses on setting road safety categories for road risk mapping assisting in the efficient use of limited financial resources to address road safety problems. Analysis of the literature shows that the prediction of road accident rates is also useful for determining the safest geometrical parameters at the design stage in response to the characteristics and behaviour of drivers (Biancardo, Russo, Zhang, \& Veropalumbo, 2019; Biancardo, Russo, Žilionienè, \& Zhang, 2017). 


\section{Case study}

Lithuanian roads fall into the categories of national and local roads considering the traffic flow, the social and economic importance. This study analyses national roads. According to the data provided by the Lithuanian Road Administration under the Ministry of Transport and Communications of the Republic of Lithuania, the road network of national significant amounted to $21237.637 \mathrm{~km}$ in 2019. The mentioned roads are divided into main, national, and regional roads.

Data generated by the Lithuanian Automobile Road Information System LAKIS (abbreviation from Lithuanian), i.e. data on road significance, road category, annual average daily traffic ( $A A D T$, vehicle per day), traffic flow composition on links, traffic volume and traffic flow composition at crossings are evaluated to conduct road safety assessment in Lithuania.

Historical road accident data for the period 2014-2018 were collected by Lithuanian Road Police Service and used for the expected road accidents. Road accident data were analysed according to accident type and accident severity. Road accident types were merged into three classes: vehicle accident, light traffic accident (collision with a bicycle and collision with a pedestrian) and accidents involving animals. To assess the expected severity of accidents and for defining road safety categories, accident data have been divided into two groups - fatal road accidents and injury road accidents.

\section{Methodology and results}

The research methodology covers five steps:

1) collecting and processing various data sources;

2) expecting road fatalities in road sections;

3) calculating the expected road fatal accident density on road links;

4) classifying the expected road fatal accident density;

5) mapping safety categories.

For determining road safety categories in this study, the authors have selected the road fatalities criterion to assess the severity of road accidents.

Many scientists (Elvik, 2008; Hauer 1997; Hauer, Harwood, Council, \& Griffith, 2020; Montella, 2010; Persaud, Lan, Lyon, \& Bhim, 2010; Stipancic, Miranda-Moreno, Saunier, \& Labbe, 2018) point out that the empirical Bayes (EB) method has been well-developed in the field of road safety and have been used for over 30 years. When applying the empirical Bayes method, the expected number of road accidents on a 
specific location is estimated by weighting the historical number of road accidents on the location and the general number of road accidents for similar sites estimated by road accident prediction models (Hauer, 1997; Persaud \& Lyon, 2007; Sørensen \& Elvik, 2007):

$$
\begin{aligned}
& E\left(\frac{\lambda}{r}\right)=\alpha \lambda+(1-\alpha) r, \\
& \alpha=\frac{1}{1+\frac{\lambda}{k}},
\end{aligned}
$$

(Sørensen \& Elvik, 2007)

(Sørensen \& Elvik, 2007)

where $E\left(\frac{\lambda}{r}\right)$ - the local expected number of accidents on a specific location; $\lambda$ - the general expected number of accidents estimated by road accident prediction models; $r$ - the historical number of accidents on the location; $k$ - the inverse value of the overdispersion parameter.

Road accident prediction models for the Lithuanian road network have been developed concerning the observed road, traffic, and historical accident data on the period 2014-2018. Different road accident prediction models are used for road links and crossings. The accident model for road links is based on the number of road accident per distance driven by vehicles, whereas that for crossings refers to the number of road accident per number of vehicles entering the crossing area. Thus, considering the above information and considering accident models defining the risk of road accidents on the road elements of a similar environment, the road network is divided into the homogeneous groups of road links and crossings in line to specific criteria. The homogenous groups of road links are classified in line to the following criteria: road significance and road category, $A A D T$ and traffic flow composition. Based on the above criteria, 40 sub-groups of homogenous road links have been determined. The roads of national significance in Lithuania have been divided into 10013 homogenous road links. Primary data on the groups of homogeneous road links are given in Table 1 also shows the risk of road accidents and road fatalities in each homogeneous group. Risk is calculated assessing appropriately the ratio of road accidents and road fatalities to mileage for the period 2014-2018 considering both the length of the homogeneous group and the AADT. The highest risk of road accidents has been identified on regional roads twice exceeding the overall average risk (6.8) of the entire national road network and reaching 14.5 road accident per 100 million vehicle kilometres travelled. Correspondingly, the risk of fatality is by 1.84 times higher 
than the average value (0.95) and makes 1.98 fatalities per 100 million vehicle kilometres travelled.

Homogenous crossing groups have been classified in line to three criteria: the type of the crossing, road significance (cases of threeleg ( $\mathrm{T}$ ) and four-leg (X) crossings), traffic flows at the crossing (crossings have been grouped depending on the proportion of vehicles entering the crossing from a minor road to the whole number of vehicles entering the crossing based on this criterion). Based on the above criteria, 2826 crossings on the roads of national significance in Lithuania have been divided into 21 sub-groups of homogenous crossings. The basic data on homogeneous crossing groups are presented in Table 2. The risk of road accidents and road fatalities has been calculated assessing the number of road accidents and fatalities for the period 2014-2018 considering the vehicles entering the crossing appropriately. It is noteworthy that the highest risk has been estimated at traffic light regulated crossings accepted to be sufficiently safe. The number of regulated crossings is small (24 in total), and therefore random variation and possible data mistakes might lead to higher risk.

Table 1. Data on the groups of homogenous road links

\begin{tabular}{|c|c|c|c|c|c|}
\hline \multirow{2}{*}{\multicolumn{2}{|c|}{ Road }} & \multirow{3}{*}{$\begin{array}{c}\text { Road link } \\
\text { in the road } \\
\text { sub-group, } \\
\text { number }\end{array}$} & \multirow{3}{*}{$\begin{array}{l}\text { Length }^{(2)} \\
\text { km }\end{array}$} & \multirow{2}{*}{\multicolumn{2}{|c|}{$\begin{array}{c}\text { Road accident } \quad \text { Fatality } \\
\text { risk per } 100 \mathrm{~m} \text { ln vehicles }\end{array}$}} \\
\hline & & & & & \\
\hline group & sub-group ${ }^{(1)}$ & & & km & km \\
\hline AM & AM & 26 & 314 & 2.1 & 0.37 \\
\hline I & $\begin{array}{l}\text { Roads } \\
\text { with a median lane }\end{array}$ & 74 & 258 & 2.7 & 0.34 \\
\hline \multirow{2}{*}{ II-III } & Main & 181 & 1044 & 4.4 & 0.92 \\
\hline & National and Regional & 348 & 1348 & 6.8 & 1.12 \\
\hline \multirow{3}{*}{$\begin{array}{l}\text { IV, V } \\
\text { and less }\end{array}$} & Main and National & 692 & 2942 & 7.7 & 1.22 \\
\hline & Regional IV & 613 & 1199 & 12.8 & 1.98 \\
\hline & Regional $\mathrm{V}$ and less & 4120 & 10517 & 14.5 & 1.92 \\
\hline \multirow{4}{*}{$\begin{array}{l}\text { Urban } \\
\text { roads }\end{array}$} & Main & 98 & 107 & 5.8 & 0.72 \\
\hline & National & 786 & 761 & 12.1 & 0.71 \\
\hline & Regional & 3075 & 2726 & 13.5 & 1.35 \\
\hline & Total & 10013 & 21216 & $6.8^{(3)}$ & $0.95^{(3)}$ \\
\hline
\end{tabular}

Notes: ${ }^{(1)}$ - each road group is further subdivided into sub-groups in line to AADT,

and the composition of traffic flow; ${ }^{(2)}-2018$ data; $^{(3)}$ - the average risk is the weighted

average of the risks of all road accident groups. 
Table 2. Data on the groups of homogenous road crossings

\begin{tabular}{lccccc}
\hline \multirow{2}{*}{$\begin{array}{c}\text { Type } \\
\text { of the crossing }\end{array}$} & \multicolumn{2}{c}{ Number of homogenous crossings } & Road accident & Fatality \\
\cline { 2 - 6 } & $\mathbf{0 - 5} \mathbf{\%}^{(1)}$ & $\mathbf{6 - 1 5 \%}$ & no less than $\mathbf{1 6 \%}$ & $\begin{array}{c}\text { risk per } \mathbf{1 0 0} \mathbf{~ m l n} \\
\text { entering vehicles }\end{array}$ \\
\hline T, main road & 101 & 50 & - & 4.0 & 0.69 \\
T, minor road & 358 & 624 & 724 & 8.7 & 1.15 \\
X, main road & 60 & 35 & 19 & 7.0 & 1.54 \\
X, minor road & 76 & 189 & 357 & 12.1 & 1.18 \\
Grade separated & 29 & 26 & 36 & 2.0 & 0.36 \\
Roundabout & 3 & 18 & 76 & 8.1 & 0.83 \\
Regulated & 3 & 5 & 16 & 14.5 & 0.45 \\
\hline \multicolumn{1}{c}{ Total } & 630 & 947 & 1249 & $7.0^{(2)}$ & $0.92^{(2)}$ \\
\hline
\end{tabular}

Notes: ${ }^{(1)}$ - the proportion of vehicles entering the crossing from the minor road;

(2) - the average risk is the weighted average of the risks of all accident groups.

The type of accident prediction model for the number of accidents on links is Eq. (3):

$$
\lambda_{\text {link }}=e^{B \text { constant }} A A D T^{B} L(5) \cdot(365) A A D T 10^{-3},
$$

where $e^{B \text { constant }}$ - constant risk; $e$ - Napier constant as the basis of the natural logarithm function, $e \approx 2.71828 ; B$ - coefficient of the model calculated by simulating a five-year (2014-2018) period historical road accident data in the homogeneous group of roads; $A A D T$ - annual average daily traffic (vehicle per day on the road link) vpd; $L$ - length of the road link, km.

The type of road accident prediction model for the number of accidents at crossings is (Eq. (5)):

$$
\lambda_{\text {crossing }}=e^{B \text { constant }} \text { Share of incoming vehicles fromminor road }{ }^{B}(5) \cdot(365)
$$

$$
\text { Entering vehicles } 10^{-3} \text {, }
$$

where $e^{B \text { constant }}$ - constant risk: $e$ - Napier constant as the basis of the natural logarithm function, $e \approx 2.71828 ; B$ - coefficient of the model calculated by modelling a five-year (2014-2018) period road accident data in the homogeneous group of crossings; the Share of traffic from the minor road, \%; Entering vehicles are the number of incoming vehicles, 1000 veh.

The coefficients of the model have been calculated using five-year historical road accident data in three categories of accidents (Table 3). 

in SPSS employing the GENLIN procedure to explain variations in the number of road accidents (each accident type separately) using:

- Poisson as the probability distribution of the dependent variable;

- interaction between factors in the road group and $A A D T$ as independent variables;

- vehicle kilometres as an offset term, i.e. modelling actual risk instead of the number of accidents.

$B$-coefficient for crossings (Table 5) were calculated respectively for crossings. However,

- number of the vehicles arriving at the crossing was used instead of vehicle kilometres;

- interaction between factors in the crossing group and the share of vehicles arriving from the minor road as independent variables;

- using the number of arriving vehicles as an offset term instead of vehicle kilometres.

While calculating the expected road accident numbers, term $B$ is applied in equation $e^{B}$, because the used link function is logarithmic, i.e. the variables used in modelling were logarithmic.

Table 3. The number of victims by road accident type on links and crossings for the period 2014-2018

\begin{tabular}{|c|c|c|c|c|c|}
\hline \multirow{3}{*}{ Road accident type } & \multirow{3}{*}{ Road accident category } & \multicolumn{4}{|c|}{ Road accidents } \\
\hline & & \multicolumn{2}{|c|}{ at crossing } & \multicolumn{2}{|c|}{ on link } \\
\hline & & Injured & Killed & Injured & Killed \\
\hline Collision & \multirow{8}{*}{ Vehicle } & 449 & 42 & 1483 & 190 \\
\hline Collision with a motorcycle & & 17 & 5 & 52 & 5 \\
\hline Collision with a moped & & 7 & 0 & 18 & 4 \\
\hline Collision with an obstacle & & 12 & 1 & 107 & 25 \\
\hline Overturning & & 111 & 12 & 910 & 75 \\
\hline $\begin{array}{l}\text { Collision with a standing } \\
\text { vehicle }\end{array}$ & & 7 & 0 & 48 & 4 \\
\hline Collision with a rail vehicle & & 0 & 0 & 2 & 2 \\
\hline Other types of accidents & & 86 & 4 & 643 & 62 \\
\hline Collision with a bicycle & \multirow{2}{*}{ Light traffic } & 75 & 9 & 278 & 46 \\
\hline Collision with a pedestrian & & 168 & 34 & 575 & 176 \\
\hline \multirow[t]{2}{*}{ Collision with an animal } & Accidents involving animals & 6 & 1 & 103 & 4 \\
\hline & Total & 938 & 108 & 4219 & 593 \\
\hline
\end{tabular}


Due to the limited data sample of road accidents involving animals on road links, the risk values of the prediction model are inaccurate (Table 4). As for the crossings, the number of the accidents involving animals is small (6 accidents in five years in total), and thus appropriate coefficients of the model are difficult to build up (Table 5).

The below example refers to calculating the expected road accidents (accident category-vehicle) on the link. The examined A1 link covers the section from $17.971 \mathrm{~km}$ to $24.70 \mathrm{~km}$. The link belongs to a homogeneous

Table 4. The coefficients of the model for road accidents on links

\begin{tabular}{|c|c|c|c|c|c|c|c|}
\hline \multirow{3}{*}{\multicolumn{2}{|c|}{ Road group }} & \multicolumn{6}{|c|}{ Road accident category } \\
\hline & & \multicolumn{2}{|r|}{ Vehicle } & \multicolumn{2}{|c|}{ Light traffic } & \multicolumn{2}{|c|}{$\begin{array}{c}\text { Accidents involving } \\
\text { animals }\end{array}$} \\
\hline & & $B^{(1)}$ & Significance ${ }^{(2)}$ & $B^{(1)}$ & Significance ${ }^{(2)}$ & $B^{(1)}$ & Significance $^{(2)}$ \\
\hline \multicolumn{2}{|c|}{$\begin{array}{l}\text { B-coefficient } \\
\text { for constant }\end{array}$} & -7.515 & & -9.871 & & -11.136 & \\
\hline \multicolumn{2}{|c|}{$k$-value } & 4.90 & & 0.87 & & 1.09 & \\
\hline AM & AM & -0.365 & 0.0 & -0.332 & 0.0 & -0.183 & 18.3 \\
\hline 1 & $\begin{array}{l}\text { Roads } \\
\text { with } \\
\text { a median } \\
\text { lane }\end{array}$ & -0.317 & 0.0 & -0.269 & 0.0 & -0.274 & 4.0 \\
\hline \multirow[b]{2}{*}{$\|-I I I$} & Main & -0.313 & 0.0 & -0.243 & 0.0 & -0.211 & 16.1 \\
\hline & $\begin{array}{l}\text { National } \\
\text { and } \\
\text { Regional }\end{array}$ & -0.280 & 0.0 & -0.183 & 0.0 & -0.228 & 15.5 \\
\hline \multirow{3}{*}{$\begin{array}{l}\text { IV, V } \\
\text { and } \\
\text { less }\end{array}$} & $\begin{array}{l}\text { Main } \\
\text { and } \\
\text { National }\end{array}$ & -0.278 & 0.0 & -0.201 & 0.0 & -0.232 & 17.4 \\
\hline & $\begin{array}{l}\text { Regional } \\
\text { IV }\end{array}$ & -0.234 & 0.0 & -0.108 & 1.8 & -0.377 & 7.3 \\
\hline & $\begin{array}{l}\text { Regional } \\
\mathrm{V} \\
\text { and less }\end{array}$ & -0.248 & 0.0 & -0.166 & 0.1 & -0.481 & 4.4 \\
\hline \multirow{3}{*}{$\begin{array}{l}\text { Urban } \\
\text { roads }\end{array}$} & Main & -0.300 & 0.0 & -0.078 & 2.3 & -3.297 & 100.0 \\
\hline & National & -0.263 & 0.0 & 0.009 & 80.5 & -0.500 & 1.6 \\
\hline & Regional & -0.258 & 0.0 & -0.012 & 77.8 & - & - \\
\hline
\end{tabular}


group of road sections "Roads with a median lane". The length of the examined link is $6.729 \mathrm{~km}, A A D T-31180 \mathrm{vpd}$. For the period 20142018, 5 road accidents (accident category - vehicle) occurred on this link. To calculate the expected number of accidents on the link mentioned above, first, the road accident prediction model $\lambda$ (Eq. (3) and Table 4) was estimated:

$\lambda=\mathrm{e}^{-7,515} \cdot 31180^{-0,317} \cdot 5 \cdot 365 \cdot 6.729 \cdot 31180 \cdot 10^{-3}=7.85$ accidents $/ 5$ year.

At the next stage, the empirical Bayes method (Eqs (1) and (2)) was applied to calculate weight $\alpha$ and the expected number of accidents on the link:

$$
\alpha=\frac{1}{1+\frac{7.85}{4.90}}=0.384314
$$

$E=0.384313 \cdot 7.85+(1-0.384313) \cdot 5=6.095$ road accident per 5 year or 1.22 road accident per year.

Using the empirical Bayes method for all homogenous road links and crossings of national significance in Lithuania, the expected road accidents have been calculated. At the final stage, for assessing historical accident data, fatal road accidents or injuries road accident have been

Table 5. The coefficients of the model for road accidents at crossings

\begin{tabular}{lcccc}
\hline \multirow{2}{*}{\multicolumn{1}{c}{ Crossing type }} & \multicolumn{3}{c}{ Vohicle } & \multicolumn{2}{c}{ Light traffic $^{$\cline { 2 - 4 }$}$} & \multicolumn{3}{c}{ Significance ${ }^{(2)}$} & $\boldsymbol{B}^{(1)}$ & Significance $^{(2)}$ \\
\cline { 2 - 5 } & $\boldsymbol{B}^{(1)}$ & -10.638 & 0.288 & -11.969 \\
\hline B-coefficient for constant & \multicolumn{3}{c}{0.6} & 0.0 \\
\hline T, main road & 0.132 & 0.0 & 0.531 & 0.0 \\
T, minor road & 0.332 & 0.0 & 0.399 & 0.0 \\
X, main road & 0.348 & 0.0 & 0.516 & 0.0 \\
X, minor road & 0.470 & 1.6 & -0.268 & 6.6 \\
Grade separated & -0.162 & 0.6 & 0.156 & 16.7 \\
Roundabout & 0.161 & 0.0 & 0.593 & 0.0 \\
Regulated by traffic light & 0.368 & & & \\
\hline
\end{tabular}

Notes: (1) - B-coefficient from the model to be used in calculating the effect of $A A D T$; (2) - the significance of the $B$-coefficient expressed as a percentage representing the possibility that such effect is received from random variation and figures received from the model have been multiplied by 100 to show percentage. 
considered and made it possible to expect the accidents severity, i.e. whether it has been a fatal road accident or an injury road accident. A complete accident prediction database for each homogeneous road link or crossing as well as data on the expected fatal and injuries road accidents allow calculating relative accident rates the use of which for assessing road network safety is described in the next chapter of this paper.

\section{Assessment of the Main Road Network in Lithuania considering the Expected Fatal Accident Density}

For the next stage of determining the categories of road network safety, the main roads with a total length of $1728.80 \mathrm{~km}$ in Lithuania have been selected. It is recommended using the density of the expected road fatalities to create network safety categories to assess the severity of road accidents and considering the varying lengths of homogeneous road links. This density represents the expected number of road fatality per $100 \mathrm{~km}$ of the road per year. Although $A A D T$ is scarcely considered for calculating the density of road accidents, in any case, this parameter has already been considered when predicting road accidents on each road link. Certainly, road safety categories are created using other relative accident rates such as fatal accident rate or accident rate. However, $A A D T$ has a significant effect on calculating accident rate, and therefore low rather than high-volume roads face a higher risk. Thus, for determining road safety categories on high-volume roads, using the road accident density indicator is recommended.

Table 6. Data on road safety categories

\begin{tabular}{llccc}
\hline Safety category & $\begin{array}{c}\text { Group limits, } \\
\text { expected road } \\
\text { fatalities/100 road } \\
\mathbf{~ k m ~}\end{array}$ & $\begin{array}{c}\text { Road } \\
\text { length } \\
\text { in the } \\
\text { group, } \mathbf{k m}\end{array}$ & $\begin{array}{c}\text { Share } \\
\text { of road } \\
\text { length, \% }\end{array}$ \\
\hline $1^{\text {st }} \quad$ Low risk (safetest) & below 1.94 & 450.7 & 26.1 \\
& roads & $1.94-2.28$ & 263.0 & 15.2 \\
$2^{\text {nd }} \quad$ Low-medium risk & $2.28-2.60$ & 323.7 & 18.7 \\
$3^{\text {rd }} \quad$ Medium risk & $2.67-3.33$ & 360.4 & 20.8 \\
$4^{\text {th }} \quad$ Medium-high risk & $3.33-4.49$ & 331.0 & 19.1 \\
$5^{\text {th }}$ & High risk & & & \\
\hline
\end{tabular}


The values of the fatal accident density on main roads varies from 0.89 to 8.20 expected road fatality per $100 \mathrm{~km}$ on the road, whereas the average value makes 2.59 of road fatality per $100 \mathrm{~km}$ of the road. The calculated values of the expected fatal accident density on main roads are divided into five intervals, i.e. all links of the examined roads fall into five road safety categories (Table 6) according to the expected fatal accident density, to identify the most dangerous roads. Risk intervals have been calculated applying statistical software SPSS-syntax and quantiles appearing as one of the main characteristics of the positioned data and dividing the ordered array into five, approximately equal, intervals. The map of road safety categories has been created to show the most dangerous parts of the main road network (Figure 1). The limit values of road safety categories provided in Figure 1 are given in Table 6.

This map is an excellent tool for road authorities to show the roads or their links required to be prioritized to identify any hazards, faults, and deficiencies leading to road accidents fatalities. Such roads shall be subject to the targeted road safety inspection and developing priority action plans to remove any established deficiencies. Typically, this activity (safety rating) is of reactive origin characteristic of the

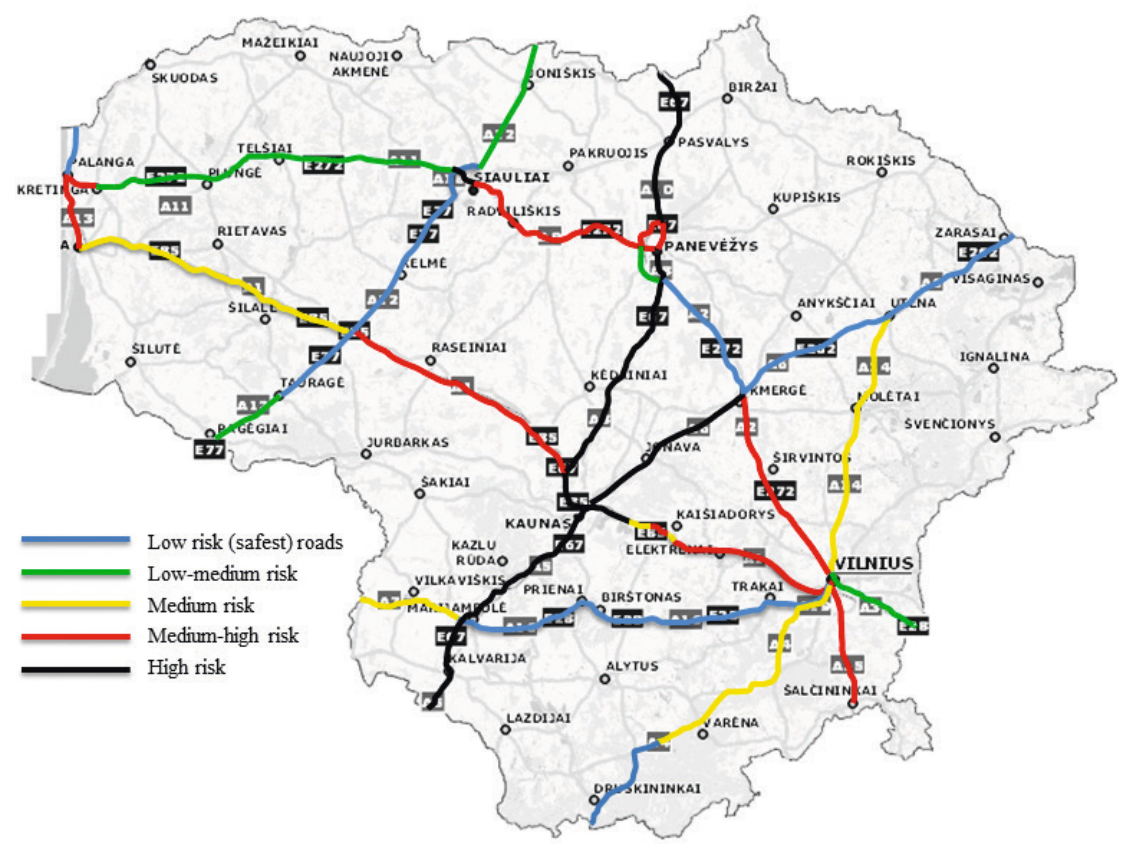

Figure 1. Road safety categories on main roads considering the expected fatal accident density in 2019 
the above-proposed rating and employing the expected road safety indicators, both "cure" and prevention are possible, i.e. the principle "prevention is better than cure" is successfully implemented. The abovedescribed procedure for setting the safety level is based on accident data and could be a part of a broader road network assessment considering (assessing) both operational and geometric characteristics of the road.

Regarding the methodology described above, road network safety levels on main roads were set in 2015 and 2018 (Peltola, Jasiūnienè, Čygaitè, \& Forsberg, 2015; Jasiūnienè, Ratkevičiūtè, \& Peltola, 2018). Comparative analysis showed (Figure 2) that a very significant decrease in the average number of the expected fatal accident density was observed comparing the periods of 2015 and 2018 when the average density dropped by 2.11 times (from 6.26 to 2.97 of road fatality per $100 \mathrm{~km}$ of the road). What could have influenced such a significant change? For expecting road accidents in 2015, historical data on road fatalities for the period 2009-2014 and for predicting accidents in 2018, historical data on road fatalities within the period 2014-2018 were used. The analysis of accident statistics for the period mentioned above shows that the number of fatalities on roads and streets generally decreased

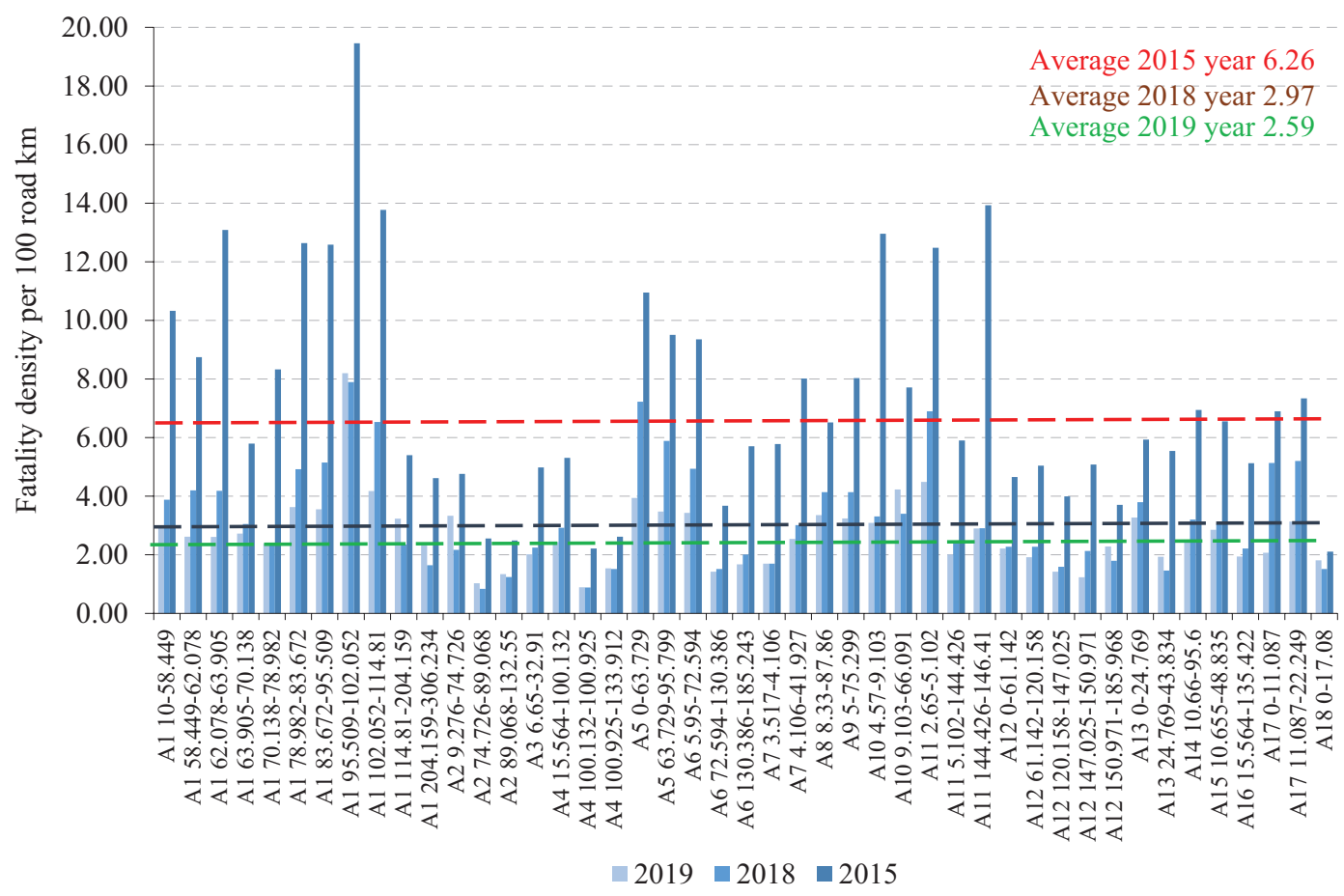

Figure 2. Variations in the expected fatal accident density on main roads 
by as much as $45 \%$ in $2009-2018$. This variation was also reflected in predicting fatal accident rates. Such a significant change on Lithuanian such as improvements in road infrastructure, advancements in cars having more and more diverse safety systems, the implementation of calming traffic measures and the education of road users. A slight but trendy decline in the expected fatal accident density was also observed, making a comparison of 2018 and 2019. Variations in the field of accident reduction are slow enough, and therefore it is advisable to set up the road network safety categories every 3-5 years. Directive 2019/1936 of the European Parliament and of the Council of 23 October 2019 Amending Directive 2008/96/EC on Road Infrastructure Safety Management recommending network-wide road safety assessment in at least once every five years.

\section{Conclusions and recommendations}

1. The evaluation of accident data in the context of network-wide road safety assessment is an essential aspect of assessing the interaction between road infrastructure and the behaviour of road users.

2. In this paper, a method is defined to identify priority roads in terms of road safety intervention in case of limited financial resources. The essential goal of the network-wide road safety assessment is to establish a priority action plan to improve road safety within the next 3-5 years. In this context, the authors of this paper recommend the use of the predicted accident data for network-wide road safety assessment and to implement preventive road safety activity in this way.

3. Applying the empirical Bayesian method, the authors of the paper carried out road accident prediction on road links and crossings of main roads in Lithuania. Homogenous groups of road links were classified by the following criteria: road significance and road category, annual average daily traffic, and composition of traffic flow. Homogenous groups of crossings were classified by the following criteria: type of crossing, road significance and traffic volume at the crossing. Road accident, road, and traffic parameters within a period of 2014-2018 were used for the prediction of road accidents.

4. The authors of the paper propose to use the index of the expected fatal accident density to carry out the ranking of main roads in terms of road safety. First, the application of the index of road 
accident density eliminates the opportunity of low-volume roads to appear at the top of the list of the most dangerous roads or links thereof. Addressing priority safety issues on high-volume roads has an effect on a larger group of road users. In addition, the parameter of annual average daily traffic is essential for the risk of accidents and has already been evaluated for the prediction of accidents on each road link or crossing. Second, the employment of data on the expected road fatalities for calculation purposes should estimate road accident severity, thus shifting the emphasis on the crossings or links of the road where the road fatalities have been predicted.

5. Based on the minimum and maximum values of the expected fatal accident density on main roads, the map of road safety categories has been made, thus dividing main roads into five safety categories. The map shows that the most hazardous road is E67 road Via Baltica that is a part of the trans-European road network.

6. The authors of this paper recommend collecting detailed data on the road geometric and operational characteristics for road authorities in order for the network-wide road safety assessments to be carried out evaluating data on predicted road accidents together with other parameters having an impact on the risk of accident or road accident severity.

\section{Funding}

The Lithuanian Road Administration under the Ministry of Transport and Communications of the Republic of Lithuania has funded the conducted research.

\section{Acknowledgement}

The authors of the paper are grateful to Mr. Harri Peltola from VTT Technical Research Centre of Finland and Mr. Mikko Virkkunen from Simsoft Oy Finland for their invaluable support in accomplishing the research.

\section{REFERENCES}

Alonso, F., Alonso, M., Esteban, C., \& Useche, S. A. (2016). Knowledge of the concepts of "black spot", "grey spot" and "high accident concentration 
sections" among drivers. American Journal of traffic and Transportation Engineering, 1(4), 39-46. https://doi.org/10.11648/j.ajtte.20160104.11

Biancardo, S. A., Russo, F., Zhang, W., \& Veropalumbo, R. (2019). Design Criteria for Improving Safety Performance of Rural Intersections. Journal of Advanced Transportation, 2019. Article ID 1232058, 11 pages. https://doi.org/10.1155/2019/1232058

Biancardo, S. A., Russo, F., Žilionienė, D., \& Zhang, W. (2017). Rural two-lane two-way three-leg and four-leg stop-controlled intersections: predicting road safety effects. The Baltic Journal of Road and Bridge Engineering, 12(2), 117-126. https://doi.org/10.3846/bjrbe.2017.14

Directive 2019/1936/EC of the European Parliament and of the Council of 23 October 2019 Amending Directive 2008/96/EC on Road Infrastructure Safety Management

Elvik, R. (2004). Traffic Safety. In M. Kutz (Ed.), Handbook of transportation engineering (Vol. 768). New York, NY, USA: McGraw-Hill.

Elvik, R. (2008). The predictive validity of empirical Bayes estimates of road safety. Accident Analysis \& Prevention, 40(6), 1964-1969. https://doi.org/10.1016/j.aap.2008.07.007

European Commission (2019). EU Road Safety Policy Framework 2021-2030 Next steps towards "Vision Zero". European Commission Staff Working Document 283 final. Brussels, 19.6.2019

Farooq, D., Moslem, S., \& Duleba, S. (2019). Evaluation of driver behavior criteria for evolution of sustainable traffic safety. Sustainability, 11(11), 3142. https://doi.org/10.3390/su11113142

González, M. P. S., Ponce, Á. T., \& Sotos, F. E. (2020). Interregional inequality and road accident rates in Spain. Accident Analysis \& Prevention, 135, 105347. https://doi.org/10.1016/j.aap.2019.105347

Hauer, E. (1996). Identification of sites with promise. Transportation Research Record, 1542(1), 54-60. https://doi.org/10.1177/0361198196154200109

Hauer, E. (1997). Observational before/after studies in road safety. Estimating the effect of highway and traffic engineering measures on road safety.

Hauer, E., Harwood, D. W., Council, F. M., \& Griffith, M. S. (2002). Estimating safety by the empirical Bayes method: a tutorial. Transportation Research Record, 1784(1), 126-131. https://doi.org/10.3141/1784-16

Henneman, L. R., Chang, H. H., Liao, K. J., Lavoué, D., Mulholland, J. A., \& Russell, A. G. (2017). Accountability assessment of regulatory impacts on ozone and PM 2.5 concentrations using statistical and deterministic pollutant sensitivities. Air Quality, Atmosphere \& Health, 10(6), 695-711. https://doi.org/10.1007/s11869-017-0463-2

Jasiūnienė, V., Ratkevičiūtė, K., \& Peltola, H. (2018, December). Road Network Safety Ranking Using Accident Prediction Models. In Conference Vision Zero for Sustainable Road Safety in Baltic Sea Region (pp. 166-176). Springer, Cham.

Montella, A. (2010). A comparative analysis of hotspot identification methods. Accident Analysis \& Prevention, 42(2), 571-581.

https://doi.org/10.1016/j.aap.2009.09.025
Road Safety

Assessment

Considering the Expected Fatal

Accident Density 
Peltola, H., Jasiūnienė, V., Čygaitė, L., \& Forsberg, A. (2015). Common Methods for Estimating the Safety Effects of Road Improvements (No. 0294).

Persaud, B., \& Lyon, C. (2007). Empirical Bayes before-after safety studies: lessons learned from two decades of experience and future directions. Accident Analysis \& Prevention, 39(3), 546-555. https://doi.org/10.1016/j.aap.2006.09.009

Persaud, B., Lan, B., Lyon, C., \& Bhim, R. (2010). Comparison of empirical Bayes and full Bayes approaches for before-after road safety evaluations. Accident Analysis \& Prevention, 42(1), 38-43. https://doi.org/10.1016/j.aap.2009.06.028

RAP-RM-2.1: RAP Road Risk Mapping Manual: Technical Specification

Sørensen, M., \& Elvik, R. (2007). Black spot management and safety analysis of road networks. Institute of transport economics.

Stipancic, J., Miranda-Moreno, L., Saunier, N., \& Labbe, A. (2018). Surrogate safety and network screening: Modelling crash frequency using GPS travel data and latent Gaussian Spatial Models. Accident Analysis \& Prevention, 120, 174-187. https://doi.org/10.1016/j.aap.2018.07.013

Strawderman, L., Rahman, M. M., Huang, Y., \& Nandi, A. (2015). Driver behavior and accident frequency in school zones: assessing the impact of sign saturation. Accident Analysis \& Prevention, 82, 118-125. https://doi.org/10.1016/j.aap.2015.05.026

Treat, J. R., Tumbas, N. S., McDonald, S. T., Shinar, D., Hume, R. D., Mayer, R. E., ... \& Castellan, N. J. (1979). Tri-level study of the causes of traffic accidents: final report. Executive summary. Indiana University, Bloomington, Institute for Research in Public Safety.

van Erp, A. M., O'Keefe, R., Cohen, A. J., \& Warren, J. (2008). Evaluating the effectiveness of air quality interventions. Journal of Toxicology and Environmental Health, Part A, 71(9-10), 583-587. https://doi.org/10.1080/15287390801997708

Varhelyi, A. (2016). Road Safety Management-The Need for a Systematic Approach. The Open Transportation Journal, 10(1). https://doi.org/10.2174/1874447801610010137 